\title{
A Novel Rotary Dryer Filled with Alumina Ceramic Beads for the Treatment of Industrial Wastewaters: Numerical Simulation and Experimental Study
}

\author{
Lixin Xie, Lingling Yang, Libo Su, Shichang $\mathrm{Xu}$ * and Wen Zhang *(D)
}

Citation: Xie, L.; Yang, L.; Su, L.; Xu, S.; Zhang, W. A Novel Rotary Dryer Filled with Alumina Ceramic Beads for the Treatment of Industrial Wastewaters: Numerical Simulation and Experimental Study. Processes 2021, 9, 862. https://doi.org/ $10.3390 /$ pr9050862

Academic Editor: Bipro R. Dhar

Received: 27 April 2021

Accepted: 9 May 2021

Published: 13 May 2021

Publisher's Note: MDPI stays neutral with regard to jurisdictional claims in published maps and institutional affiliations.

Copyright: (c) 2021 by the authors. Licensee MDPI, Basel, Switzerland. This article is an open access article distributed under the terms and conditions of the Creative Commons Attribution (CC BY) license (https:// creativecommons.org/licenses/by/ $4.0 /)$.
Tianjin Key Laboratory of Membrane Science and Desalination Technology, State Key Laboratory of Chemical Engineering, School of Chemical Engineering and Technology, Tianjin University, Tianjin 300350, China; xie_lixin@tju.edu.cn (L.X.); ylltheresa@163.com (L.Y.); 17639872778@163.com (L.S.)

* Correspondence: xu_sc1@tju.edu.cn (S.X.); zhang_wen@tju.edu.cn (W.Z.)

\begin{abstract}
In this study, a new type of rotary dryer filled with inert alumina ceramic bead (ACB) fillers was introduced to treat the industrial wastewater, e.g., the high-salt wastewater and landfill leachate. Numerical simulations based on the Discrete Element Method (DEM) on the motion trajectory of ACB fillers in the rotary dryer were conducted, and the parameters of flight structure, rotational speed, and filling degree on the dynamic behavior of ACB fillers were optimized. Under various rotational speeds and filling degrees, the experimental results fit the numerical-simulated results very well. The optimized flight configuration was the straight flights with a length of $65 \mathrm{~mm}$, and the optimized rotational speed and filling degree were $35 \mathrm{rpm}$ and $15 \%$, respectively. Under the optimized condition, both the response variables, the mass of particles in the airborne phase (MAP) and the percentage of occupied area in the airborne region (OAR), have the optimal values, in which the dryer will have a better drying performance. Besides, the lower-right area of the drum is empty which is convenient for the installation of the inlet pipe. The drying experiments of industrial wastewaters were also studied using this ACB filled rotary drum dryer under the optimized conditions. Under the optimal operational conditions, the evaporation capacities of the high-salt wastewater and landfill leachate could reach as high as $49.7 \mathrm{~kg} / \mathrm{h}$ and $90 \mathrm{~kg} / \mathrm{h}$, respectively. This study highlights the integration of evaporation and drying processes of this novel ACB filled rotary dryer and provides an efficient and zero-liquid-emission strategy for the thermal treatment of industrial wastewater.
\end{abstract}

Keywords: rotary drum dryer; discrete element method; flight configuration; operational conditions; industrial wastewaters

\section{Introduction}

With the expansion of industrial development, a large quantity of high-salt wastewater is generated and accumulated, posing a serious potential hazard to the ecological environment and mankind. These wastewaters usually come from the coal chemical, agricultural production, electroplating, and leather industries, and have a complex composition, which is hard to treat. Because of the high salts, the biological methods are strongly inhibited. As a result, the saline wastewater is usually treated via conventional physical-chemical methods, with particularly high costs. As an alternative solution, a zero-liquid discharge strategy is proposed to minimize the waste volume, reduce the treatment cost, recover valuable resources and alleviate harmful impacts of the wastewater [1-4]. Thermal concentration is one of the zero-liquid discharge technology, which utilizes a heat source to transfer heat and vaporize the liquid phase. The traditional thermal concentration technology mainly includes multiple-effect evaporation (MEE), thermal vapor recompression (TVR), and mechanical vapor recompression (MVR) [5], with the features of large evaporators and high-energy consumption [5-7]. Therefore, novel thermal concentration systems with small volumes and low energy consumption should be developed for the efficient treatment of saline wastewater. 
The rotary dryer is a conventional facility widely used for the drying of granular materials [8,9]. The solid material enters through one end of the drum and goes out at the other end, and the drying air and the material enter into the rotary drum in a countercurrent way or a concurrent way [10]. Recently, we developed a novel rotary dryer that can utilize the waste heat from the exhaust gas to treat industrial wastewater. Unlike the traditional way of drying, some inert alumina ceramic beads (ACB) were put in the drum as fillers to increase the heat/mass transfer areas and grind the solid residues into powders [11]. The model of the novel dryer is shown in Figure 1a. The wastewater went into the drum continuously through the inlet pipe (Figure 1a), and the hot air was blown into the drum through holes around one side of the periphery, transferring heat to the wastewater. When the material was unloaded from the flights, the total wastewater was dried by the hot air and became solid powder that was attached to the surface of the ACBs. The dust produced by ACBs grinding would be blown away by the drying air and leave the drum from the other side of the periphery.
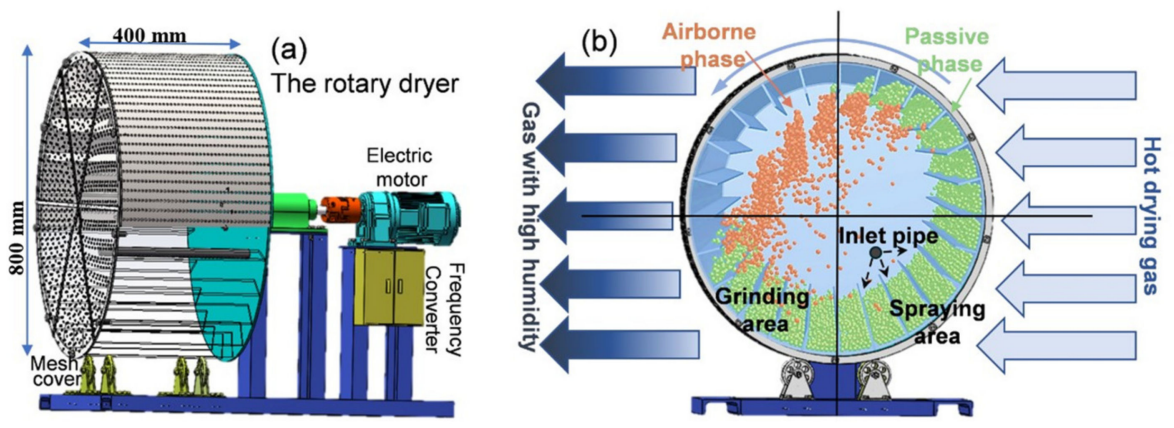

Figure 1. Schematic diagram of the rotary dryer (a) and Diagram of cross-section model of the rotary dryer (b).

The dynamic behavior of the particles in a rotary drum largely depends on operational conditions [12-14], flow properties, and the physical properties of the material [15-19], as well as the geometric configuration of the drum $[19,20]$. Many efforts have been made to analyze the particulate material's dynamic behavior from various perspectives [17,21-25]. For example, H. Henein et al. studied the effect of rotational speed on the bed motion in different rotary drums, exhibiting that transport phenomena of the particulate phase could be divided into six forms, including slipping, slumping, rolling, cascading, catarcting, and centrifuging [21] (Figure 2). Santos et al. investigated the particle behavior in a rotary drum and found that the shape of particles plays a key role in their movement [22]. Fan Geng utilized different rotating drums to compare and analyze the mixing process, revealing that the affecting factors of the mixing including the flight structure, the particles' shape, diameter, and density [24].
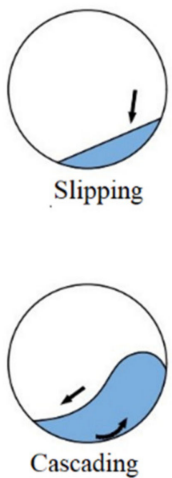
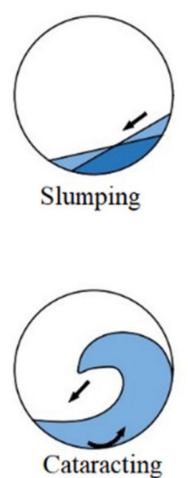
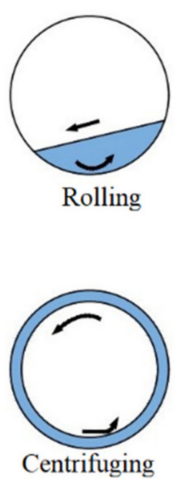

Figure 2. Modes of particle motion in the transverse plane of a rotary drum [10]. 
As stated above, the dynamic behavior of the material in drums is vitally important but difficult to understand. For this novel rotary dryer used for wastewater treatment, the behavior of the material is more complicated due to the adding of ACB fillers. Besides, the motion trajectory of the ACBs in the airborne phase (Figure 1b) will also affect the installation of the inlet pipe, and thus influence the drying performance of the rotary dryer. Although plentiful studies have been done on the mixing process of the supplied materials, such as wood chips [26], cokes [27], and other agricultural products [28] in rotary dryers, there is little research about the motion of fillers in the rotary drum. As we know, the physical properties, such as density, hardness, and size of fillers are totally different from the supplied materials. Therefore, it is necessary to study filler dynamic behavior in a rotary dryer to optimize the configuration and operational condition of the dryer, and thus to improve the drying performance. Besides, as mentioned above, we also need to obtain a flow regime that can make the right-half spraying area empty to place the inlet pipe (Figure 1b) for inlet wastewater, which urges us to understand the transport process of the ACBs in the rotary drum deeply.

Consequently, we performed a numerical simulation to investigate the motion trajectory of the ACB fillers in the airborne phase. And the discrete element method (DEM) was employed to conduct the simulation since it can fully resolve the movement and interaction of all particles in the investigated system [16]. Three crucial parameters, including the flight structure, rotational speed, and fillers filling degree were optimized, and the experimental results were compared with the simulated results. Under the optimized condition, we employed this rotary drum dryer to treat the high-salt wastewater and landfill leachate. We hope these simulations and experiments will be useful for the further engineering application of thermal concentration technology using a rotary drum for wastewater treatment.

\section{Simulations and Experiments}

\subsection{DEM Simulation}

We conducted the simulations using DEM [29-32], in which Newton's second law was used to fit the particle motions. The soft sphere model is used to calculate the interactive forces of particle-particle and particle-wall, in which the contact forces between particles are usually simplified as damping vibration. We also assume that the collisions between particles are elastic collisions and the Hertz-Mindlin nonlinear model was used as a contact model. Besides, the value of the time step is usually considered as $25 \%$ of the Rayleigh time step [33,34]. According to Newton's law of motion, the motions of particle $i$ can be described by Equations (1) and (2).

$$
\begin{gathered}
m_{i} \frac{d \overrightarrow{\boldsymbol{v}_{i}}}{d t}=\sum_{j}\left(\overrightarrow{\boldsymbol{F}_{n, i j}}+\overrightarrow{\boldsymbol{F}_{t, i j}}\right)+m_{i} \overrightarrow{\boldsymbol{g}} \\
I_{i} \frac{d \overrightarrow{\boldsymbol{\omega}}_{i}}{d t}=\sum_{j} \overrightarrow{\boldsymbol{M}}_{i}
\end{gathered}
$$

In the above equations, $\vec{v}_{i}, m_{i}, \vec{\omega}_{i} I_{i}$, and $\vec{g}$ are the translational velocity, mass, angular velocity, moment of inertia of particle $i$ and the gravity acceleration constant, respectively. $\vec{M}_{i}$ is the torque acting on the particle i. $\vec{F}_{n, i j}$ and $\vec{F}_{t, i j}$ are the normal and tangential forces between particle $i$ and another particle $j$, respectively.

They can be written as:

$$
\begin{gathered}
\overrightarrow{F_{n, i j}}=k_{n} \overrightarrow{\delta_{n, i j}}-\eta_{n} \overrightarrow{v_{r, i j}} \\
\overrightarrow{F_{t, i j}}=k_{t} \overrightarrow{\delta_{t, i j}}-\eta_{t} \overrightarrow{v_{s, i j}}
\end{gathered}
$$


$\overrightarrow{\delta_{n, i j}}$ and $\overrightarrow{\delta_{t, i j}}$ are the normal and tangential deformation of particles, respectively; $\overrightarrow{v_{r, i j}}$ and $\overrightarrow{v_{s, i j}}$ are the relative velocity between two particles and the slip velocity of the particle collision point, respectively.

The related Equations of the Hertz-Mindlin model are shown in Table 1.

Table 1. Equations of the Hertz-Mindlin model.

\begin{tabular}{cc}
\hline Normal Elasic Constant & $k_{n}=\frac{4}{3} \gamma_{*} \sqrt{R^{*} \delta_{n}}$ \\
Normal viscoelastic damping constant & $\eta_{n}=-2 \sqrt{\frac{5}{6}} \beta \sqrt{S_{n} m^{*}} \geq 0$ \\
Tangential Elastic constant & $k_{t}=8_{G} * \sqrt{R^{*} \delta_{n}}$ \\
Tangential viscoelastic damping constant & $\eta_{t}=-2 \sqrt{\frac{5}{6}} \beta \sqrt{S_{t} m^{*}} \geq 0$ \\
Normal stiffness & $S_{n}=2 \gamma^{*} \sqrt{R^{*} \delta_{n}}$ \\
Tangential stiffness & $S_{t}=8 \gamma^{*} \sqrt{R^{*} \delta_{n}}$ \\
Young's modulus & $\frac{1}{Y^{*}}=\frac{\left(1-v_{i}^{2}\right)}{Y_{i}}+\frac{\left(1-v_{j}^{2}\right.}{Y_{j}}$ \\
shear modulus & $\frac{1}{G^{*}}=\frac{2-v_{i}}{G_{i}}+\frac{2-v_{j}}{G_{j}}$ \\
Equivalent particle mass & $\frac{1}{m^{*}}=\frac{1}{m_{i}}+\frac{1}{m_{j}}$ \\
Equivalent particle radius & $\frac{1}{R^{*}}=\frac{1}{R_{i}}+\frac{1}{R_{j}}$ \\
\hline
\end{tabular}

The model of the rotary drum has a diameter of $800 \mathrm{~mm}$ as well as a length of $400 \mathrm{~mm}$ and the drum is equally equipped with 24 flights (Figure $1 b$ ).

Table 2 summarizes the properties of particles and relevant contact parameters used in the simulations. For all simulations, inert alumina ceramic beads were used. The density of particulate material is $2100 \mathrm{~kg} / \mathrm{m}^{3}$ and the diameter of the particle is $13 \mathrm{~mm}$.

Table 2. Parameters used in the DEM simulations.

\begin{tabular}{ccc}
\hline & Ceramic Beads & Stainless Steel \\
\hline Density $\left(\mathrm{kg} / \mathrm{m}^{3}\right)$ & 2100 & 7900 \\
Restitution coefficient & 0.5 & 0.9 \\
Poisson ratio $(-)$ & 0.29 & 0.3 \\
Young's modulus $(\mathrm{Pa})$ & $5.16 \times 10^{7}$ & $2 \times 10^{11}$ \\
& Particle-particle & Particle-wall \\
Coefficient static friction & 0.3 & 0.5 \\
Coefficient of rolling friction & 0.01 & 0.01 \\
\hline
\end{tabular}

The effects of the flight structure, rotational speed, and bead filling degree (the ratio of beads volume occupied in the volume of the drum) on the dynamic behavior of ACBs in the airborne phase were studied. The response variables are the mass of particles in the airborne phase (MAP) and the percentage of occupied area in the airborne region (OAR). The MAP and OAR responses were obtained by delimiting the area of the airborne phase in the rotary drum. The number of beads in the airborne phase was calculated using the post-processing module of DEM software. Firstly, the area of the airborne phase was demarcated. And then, beads in the airborne phase and passive phase were marked as different colors during the motion process. Then, we could get the number of beads in the airborne phase and the area of beads occupied in the airborne.

\subsection{Experiments}

By DEM simulations, we figured out the optimized flight configuration of the dryer, with a diameter of $800 \mathrm{~mm}$ as well as a length of $400 \mathrm{~mm}$. And the drum was equally equipped with 24 straight flights with a length of $65 \mathrm{~mm}$.

On one side of the rotary drum, a steel mesh front-cover plate was attached and rotated with the drum, allowing a view into the rotary drum along the axial direction during the rotation process. The rotatory drum was driven by an electric motor, and the 
steel back-cover plate on this side was fixed. A frequency converter was used to regulate the driving speed of the electric motor and thus adjust the rotational speed (Figure 1a).

In the experimental study, we investigated the effects of the rotational speed and the filling degree on the motion behavior of ACB fillers in this novel dryer and compared the experimental results with the simulation results.

Figure 3 displays the process of the drying experiment. In the drying experiments, the wastewater was pumped into the drum continuously through the inlet pipe fixed in the lower-right area of the drum. The air passed through the blower and then was heated to the set temperatures by the air heater. The hot air was blown into the drum through holes around the periphery, transferring heat to the wastewater. The total wastewater was dried by the hot air and ground into dust powder that was attached to the surface of the ACBs. The dust powder would be blown away by the drying air and then collected.

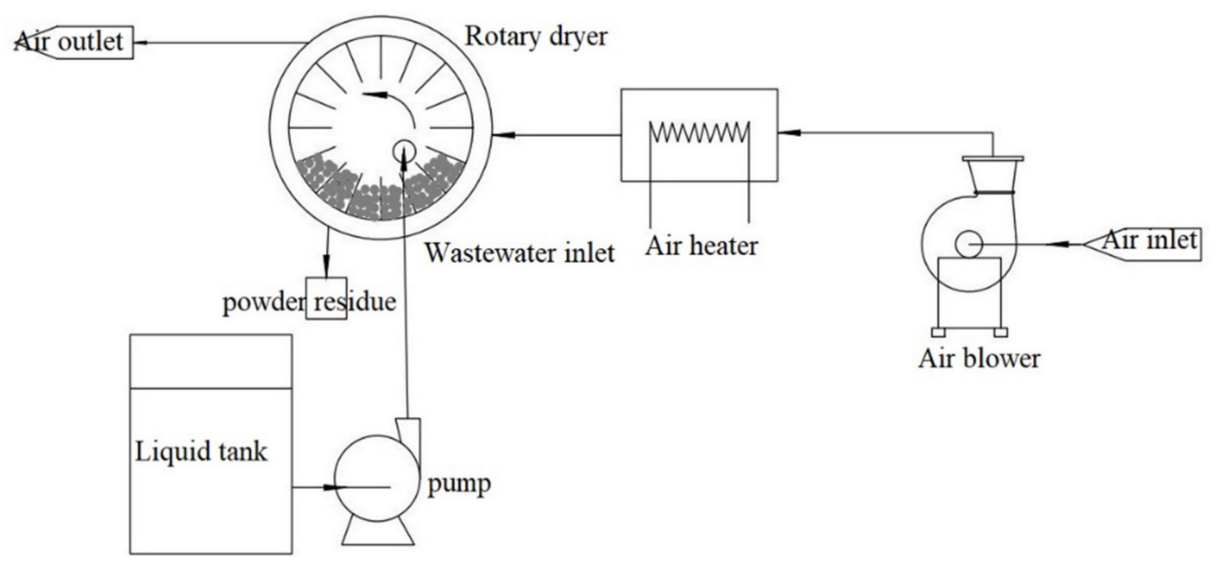

Figure 3. Flow diagram of the drying experiments.

Tables 3 and 4 display the water quality of the high-salt wastewater and landfill leachate, respectively. In the drying experiments, there was an insulated box outside the dryer to prevent heat loss. The flow rate of the hot air was $1000 \mathrm{~m}^{3} / \mathrm{h}$. In the drying experiments of high-salt wastewater, we studied the effects of rotational speed and filling degree on the drying performance of the dryer and analyzed the values of evaporation capacity. In the drying experiments of landfill leachate under the optimized rotational speed and filling degree, we investigated the effects of inlet air temperature on the drying performance of the dryer.

Table 3. Water quality index of high-salt wastewater.

\begin{tabular}{ccccccc}
\hline pH & $\begin{array}{c}\text { Total Dissolved } \\
\text { Solids (mg/L) }\end{array}$ & $\begin{array}{c}\mathrm{Cl}^{-} \\
(\mathbf{m g} / \mathrm{L})\end{array}$ & $\begin{array}{c}\mathrm{SO}_{4}{ }^{2-} \\
(\mathbf{m g} / \mathrm{L})\end{array}$ & $\begin{array}{c}\mathrm{Na}^{+} \\
(\mathbf{m g} / \mathrm{L})\end{array}$ & $\begin{array}{c}\mathrm{Ca}^{2+} \\
(\mathbf{m g} / \mathrm{L})\end{array}$ & $\begin{array}{c}\mathbf{M g}^{2+} \\
(\mathbf{m g} / \mathrm{L})\end{array}$ \\
\hline $8-10$ & 90,600 & 48,130 & 7280 & 34,200 & 469 & 131 \\
\hline
\end{tabular}

Table 4. Water quality index of landfill leachate.

\begin{tabular}{ccccccc}
\hline pH & $\begin{array}{c}\text { Ammonia } \\
\text { Nitrogen (mg/L) }\end{array}$ & $\begin{array}{c}\text { Suspended } \\
\text { Solids (mg/L) }\end{array}$ & $\begin{array}{c}\mathrm{Ca}^{2+} \\
(\mathbf{m g} / \mathrm{L})\end{array}$ & $\begin{array}{c}\mathrm{Mg}^{2+} \\
(\mathbf{m g} / \mathrm{L})\end{array}$ & $\begin{array}{c}\mathrm{Fe}^{3+} \\
(\mathbf{m g} / \mathrm{L})\end{array}$ & $\begin{array}{c}\mathrm{Cl}^{-} \\
(\mathbf{m g} / \mathrm{L})\end{array}$ \\
\hline $5.5-6.1$ & 900 & 800 & 50 & 150 & 60 & 640 \\
\hline
\end{tabular}

\section{Results and Discussions}

\subsection{The Effects of Flight Structures}

The joint angle of the two-segment flights could impact the ACB distribution in both the airborne phase and passive phase, as well as the residence time of the beads on the flights. Previous studies show that flights with two segments usually contributed to a 
greater material loading and were largely applied to different equipment [14,29]. Here, we chose the angle of the two-segment flights and the flight length to study the effects of flight structure on the ACBs transport in the airborne phase.

Figure 4 shows the flow patterns of alumina ceramic beads in the drum with different configurations of the two-segment flights. The vertical bars display the linear velocities of the beads in the drum with different joint angles of the two-segment flights. When the beads unload from the flights, the beads would do a parabolic motion and the velocities of falling beads are also getting higher when they are falling down. When the angle $\alpha$ is $90^{\circ}$, parts of the beads lifted by the flights are scattered in the airborne phase and then fall down, and there are almost no empty flights. When the angle $\alpha$ is between $100^{\circ}$ and $135^{\circ}$, the volume occupied by the beads in the airborne phase is low. However, when the angle $\alpha$ is $180^{\circ}$, the beads are cataracting in the airborne phase. And the flights between 9 o'clock position and $12 \mathrm{o}^{\prime}$ clock position discharge all the beads, in which more effective contact is obtained between the beads and the drying gas.
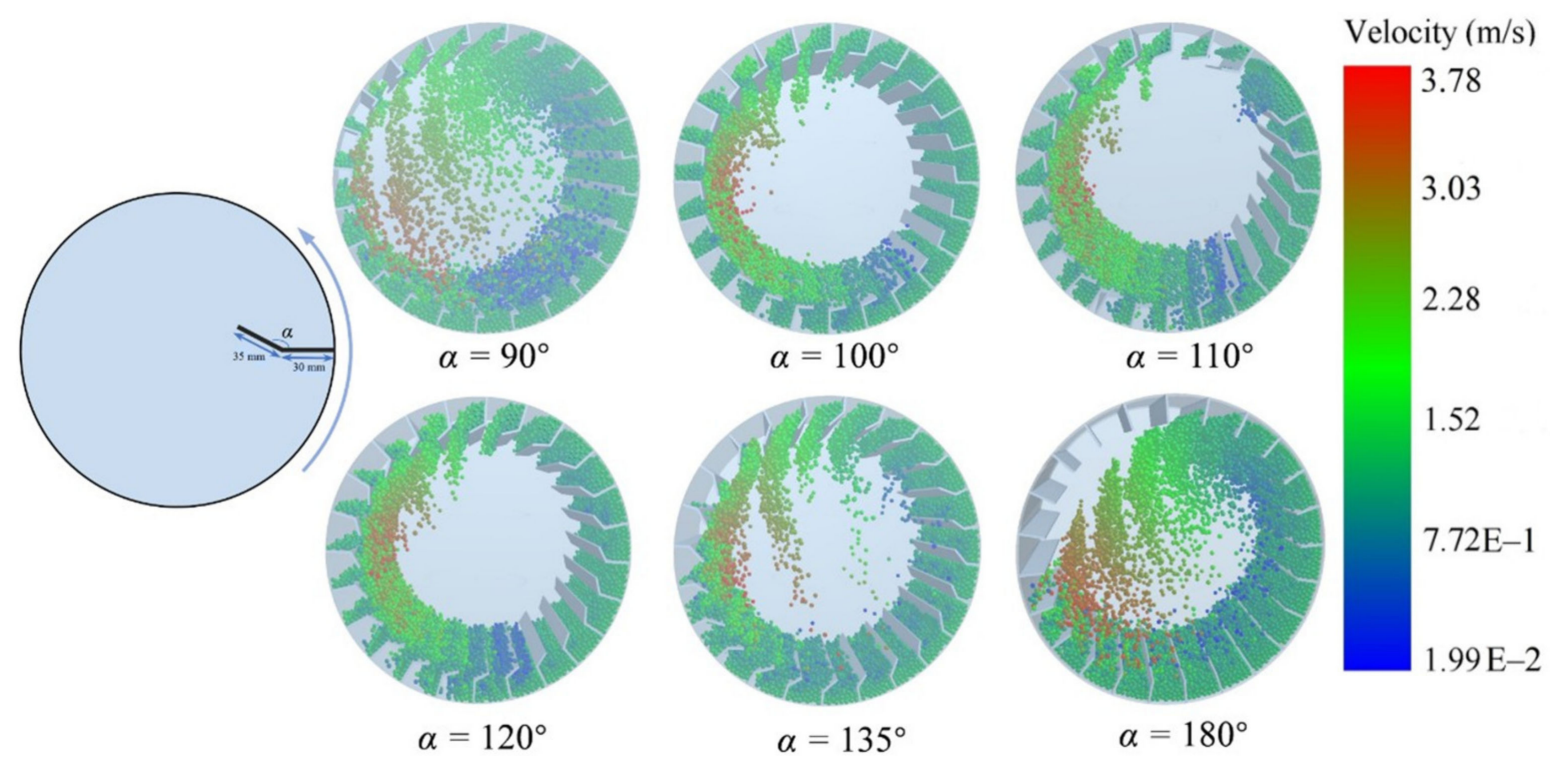

Figure 4. The motion behavior profiles of alumina ceramic beads in the drum with different two-segment flights. (Rotational speed: $35 \mathrm{rpm}$; Filling degree: 15\%).

In Figure 5a,b, the MAP and OAR responses show an oscillatory behavior over time, which could be ascribed to the periodic motion behavior of beads in the rotary drum. For the flight configuration with angle $\alpha=90^{\circ}$, more beads would be lifted by the flights compared with the angle $\alpha$ ranging from $100^{\circ}$ to $135^{\circ}$, and then unload from the flights. When the angle $\alpha$ is between $100^{\circ}$ and $135^{\circ}$, few beads are lifted by the flights and then discharge into the airborne phase, leading to small values of MAP and OAR. However, when the angle $\alpha$ is $180^{\circ}$, this configuration can provide the maximum values for MAP and OAR and the flow regime is cataracting in the airborne phase. In this flow regime, the falling beads in the airborne phase are mainly located in the left area of the rotary drum, and the beads can fall to the bottom of the drum with a high velocity. At the bottom of the drum, the beads could grind with each other and then enter into the spraying area. Besides, in this case, the lower-right area of the drum is empty and the inlet pipe could be located there to obtain a better drying performance. 

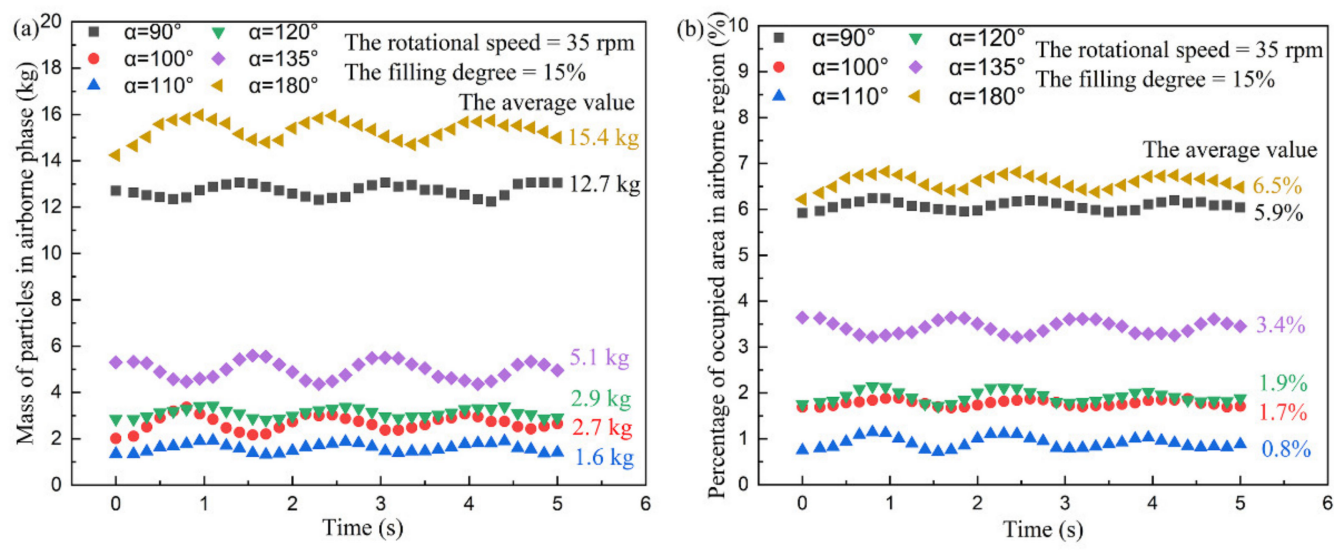

Figure 5. Dynamic behaviors of MAP (a) and OAR (b) for the drum with different joint angles of the two-segment flights.

To study the effects of flight length on dynamic behaviors of beads in the airborne phase, we chose the straight flights with different lengths of $35 \mathrm{~mm}, 50 \mathrm{~mm}, 65 \mathrm{~mm}$, and $80 \mathrm{~mm}$ to simulate the beads flow patterns, and the results are shown in Figure 6. When the flight length is $35 \mathrm{~mm}$, lots of beads could not be loaded by the fights and move at a low speed. When the flight length is $50 \mathrm{~mm}$, more beads could be loaded and discharge into the airborne phase. However, the lower-right area of the drum is partly occupied by some beads. When the flights are $65 \mathrm{~mm}$ and $80 \mathrm{~mm}$ in length, most beads could be lifted and discharge at higher altitudes, and the lower-right area of the drum is empty, which is beneficial for the installation of the inlet pipe.
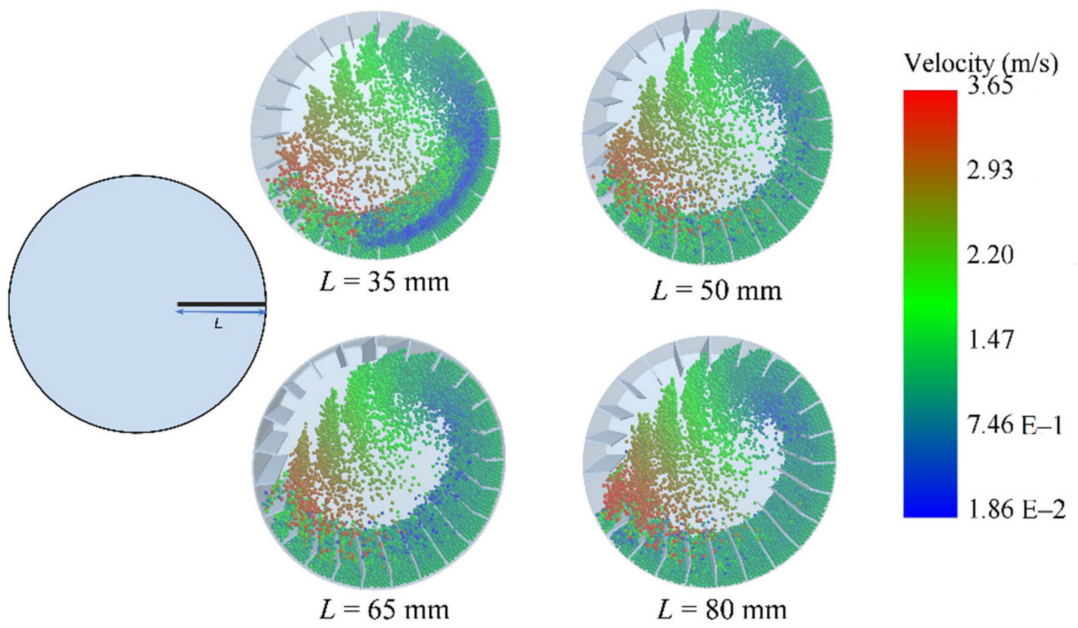

Figure 6. The motion behavior profiles of alumina ceramic beads inside the drum with flights of different lengths (Rotational speed: 35 rpm; Filling degree: 15\%).

Figure 7 displays the values of MAP and OAR in the permanent regime in the rotary drum with straight flights of different lengths. The values of MAP and OAR are constantly rising with the flight lengths ranging from $35 \mathrm{~mm}$ to $80 \mathrm{~mm}$. The longer the flights are, the more beads are lifted by flights and discharge into the airborne phase. When the flight lengths are $65 \mathrm{~mm}$ and $80 \mathrm{~mm}$, more beads exist in the airborne phase and the falling beads grind with each other in the grinding area and then enter into the spraying area. In this case, the beads and the drying gas have an efficient contact and thus high heat and mass transfer performance could be obtained. Considering the manufacturing costs, we chose the straight flight with a length of $65 \mathrm{~mm}$ as the optimized flight structure. 

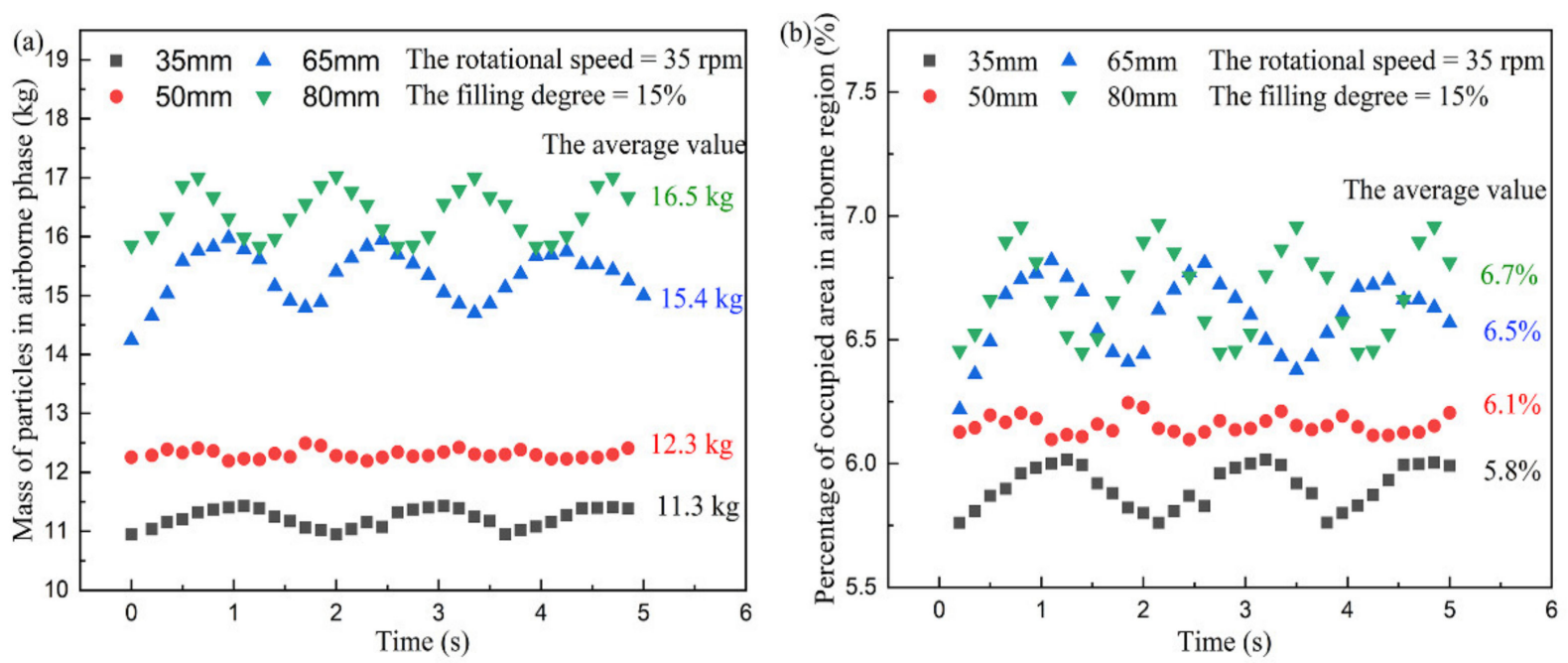

Figure 7. Dynamic behaviors of MAP (a) and OAR (b) with straight flights of different lengths.

\subsection{The Effect of Rotational Speeds}

For the simulations under different rotational speeds, we chose the optimized straight flights with a length of $65 \mathrm{~mm}$. Figure 8 shows the simulated and experimental figures of the motion behaviors of alumina ceramic beads as a function of the rotational speed. The simulated results are generally in good agreement with the experimental data for all studied conditions (at different rotational speeds). From the velocity distribution of beads, we could see that the beads grind with an initial impact velocity of $3.7 \mathrm{~m} / \mathrm{s}$. When the rotational speed is fixed at $25 \mathrm{rpm}$, the beads motion behavior takes on the regime of cascading. As the rotational speed increases to a value of $35 \mathrm{rpm}$, the beads motion behavior converts to the regime of cataracting. If the rotary speed is above $40 \mathrm{rpm}$, it could realize the transition from cataracting to centrifuging.

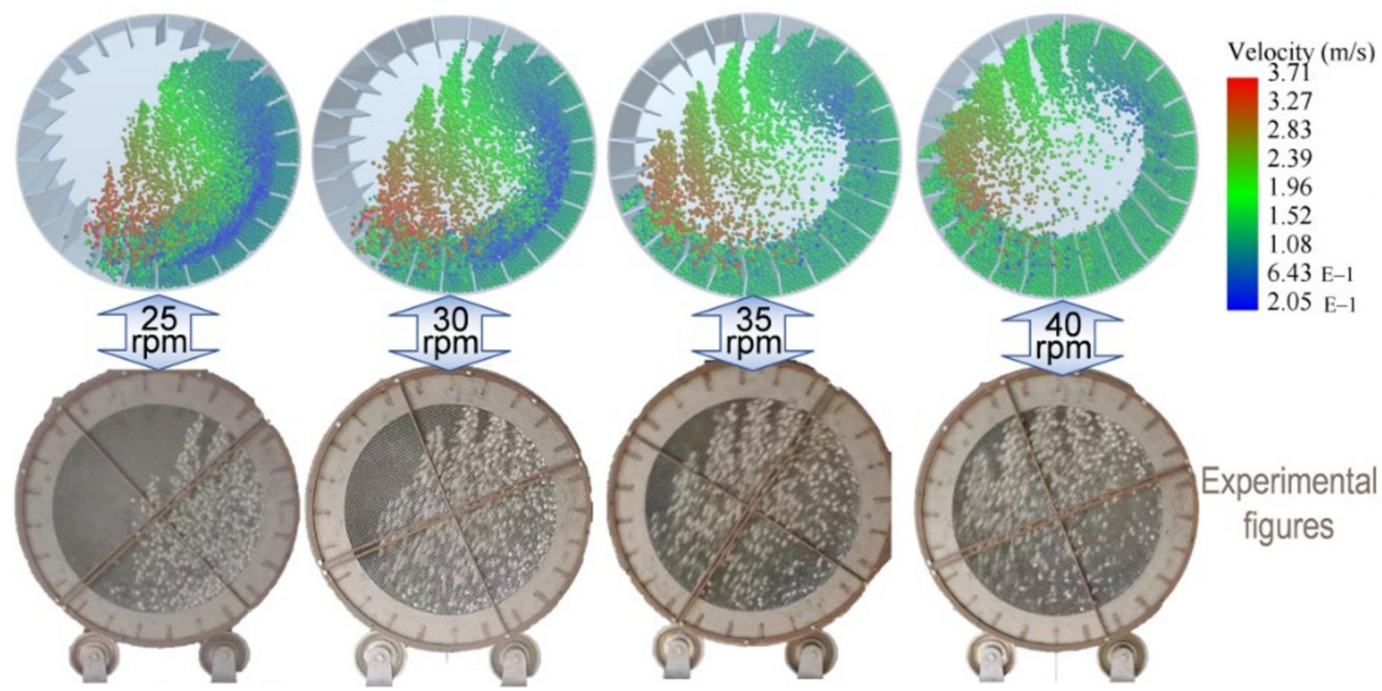

Figure 8. Experimental and simulated motion behavior profiles of alumina ceramic beads in the drum under different rotational speeds (65 mm straight flight and 15\% filling degree).

Figure 9 displays the values of MAP and OAR in the rotary drum with straight $65 \mathrm{~mm}$ flights under different rotational speeds. The values of MAP and OAR increase sharply with the rotational speeds ranging from $25 \mathrm{rpm}$ to $35 \mathrm{rpm}$ and decline when the rotational speed is $40 \mathrm{rpm}$. 

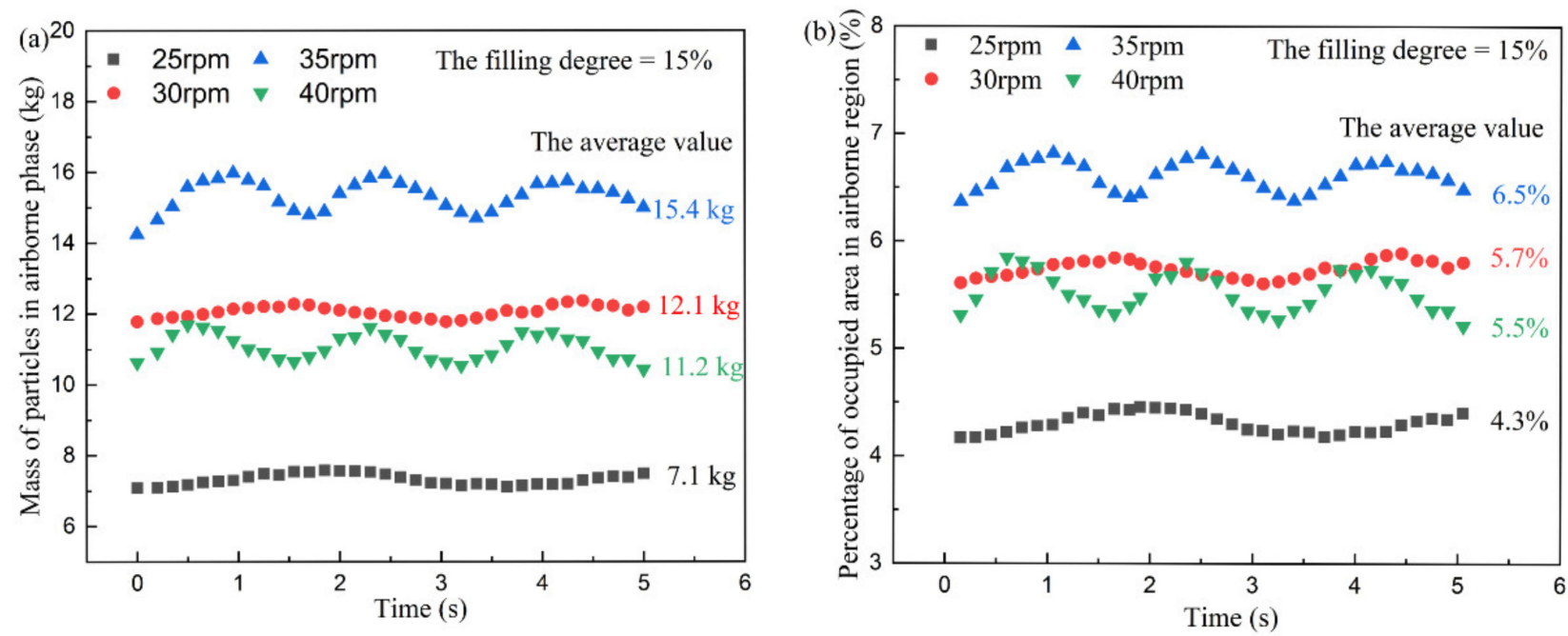

Figure 9. Dynamic behaviors of MAP (a) and OAR (b) under different rotational speeds.

As we know, the angular position of the flight where the last particle discharged is also dependent on the rotational speed intensely $[35,36]$. The centrifugal force will increase and the flights will carry the particulate material for longer distances with the increase of rotational speeds. Hence, the unloading of beads lifted by the flights will finish at a high angular position when the rotational speed is high. Therefore, when the rotational speeds increase from $25 \mathrm{rpm}$ to $35 \mathrm{rpm}$, the values of MAP and OAR also increase. When the rotational speed is as high as $40 \mathrm{rpm}$, the centrifugal force plays the dominant role in the motion of the beads, and thus the values of MAP and OAR decrease. When the rotational speed is $35 \mathrm{rpm}$, the beads in the drum are lifted by the flights to a higher angular position and then discharge into the airborne phase to form the beads curtain and obtain a larger value of MAP and OAR. Meanwhile, the flow regime is cataracting and the lower-right area of the drum is empty which is convenient for the installation of the inlet pipe. As a result, the $35 \mathrm{rpm}$ is considered as the optimized operational condition.

\subsection{The Effect of Bead Filling Degrees}

In the study of the filling degree, we chose the drum with straight flights of $65 \mathrm{~mm}$ under a rotational speed of $35 \mathrm{rpm}$. Figure 10 shows the experimental and simulated results of the beads motion behavior as a function of the filling degree. When the filling degrees range from $5 \%$ to $15 \%$, the motion patterns of alumina ceramic beads in the drum present the regime of cataracting. And then, the motion pattern converts to the regime of cascading when the filling degree is above $20 \%$.

In Figure 11, with the increase of the filling degree, the values of MAP and OAR increase as well. Since the mass of alumina ceramic beads filled in the rotary drum gets greater, the beads carried by the flights and unloading from the flights are much more than before. However, when the filling is $20 \%$, the lower-right area of the drum isn't empty and the falling beads can't grind with each other adequately. Therefore, the filling degree of $15 \%$ is best in this study. Under this circumstance, much more beads occupy the airborne phase and the falling beads grind past one another in the grinding area and then enter into the spraying area. Therefore, it could realize a better drying performance of this rotary drum.

\subsection{The Drying Experiments at Optimized Conditions}

The drying experiments were conducted under different rotational speeds and filling degrees. The flow rate of the drying air was $1000 \mathrm{~m}^{3} / \mathrm{h}$ with a temperature of $250{ }^{\circ} \mathrm{C}$. The evaporation capacity increases with the rotational speed ranging from $25 \mathrm{rpm}$ to $35 \mathrm{rpm}$ and then decreases when the rotational speed is $40 \mathrm{rpm}$ (Figure 12a). The values of the evaporation capacity increase with the filling degree increasing from $5 \%$ to $15 \%$, and then decrease when the filling degree is $20 \%$ (Figure 12b). Compared with Figures 9 and 11, the 
results of drying experiments are consistent with the simulation data very well. Table 5 shows the values of the evaporation capacities in different high-salt wastewater treatment methods and it reveals that our novel rotary dryer has a good drying performance.

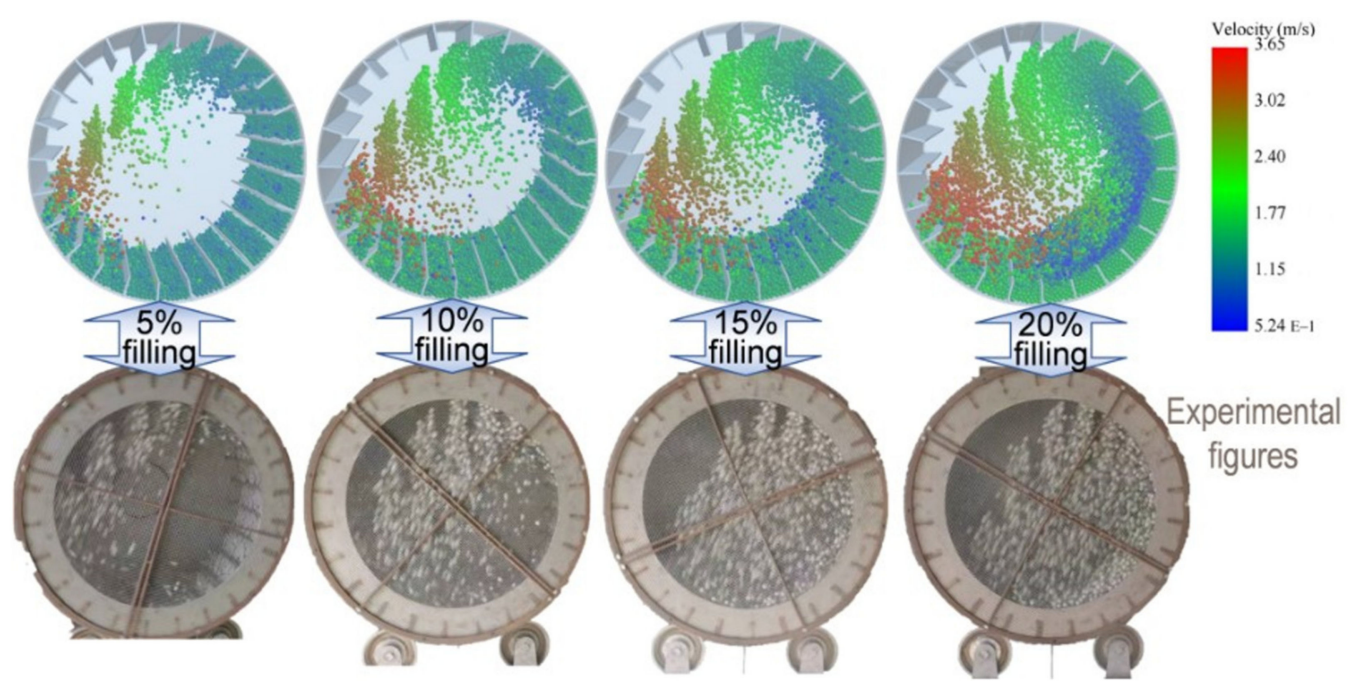

Figure 10. Experimental and simulated motion behavior profiles of alumina ceramic beads in the drum with different filling degrees (65 mm straight flight and $35 \mathrm{rpm}$ rotational speed).
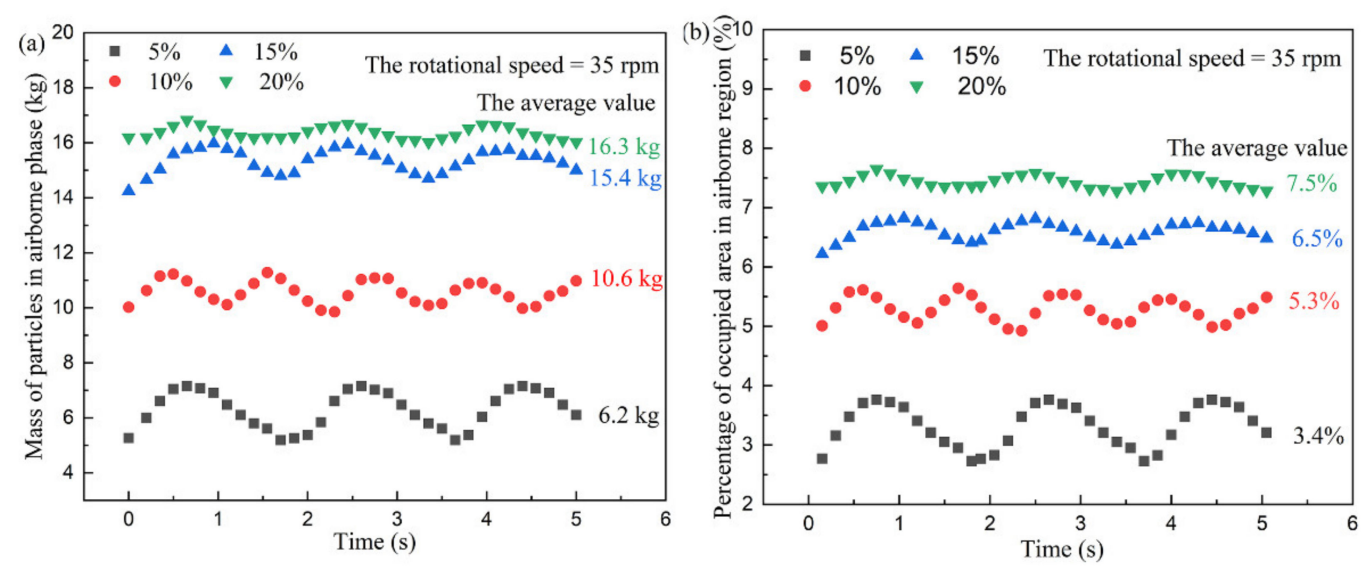

Figure 11. Dynamic behaviors of MAP (a) and OAR (b) with different filling degrees.
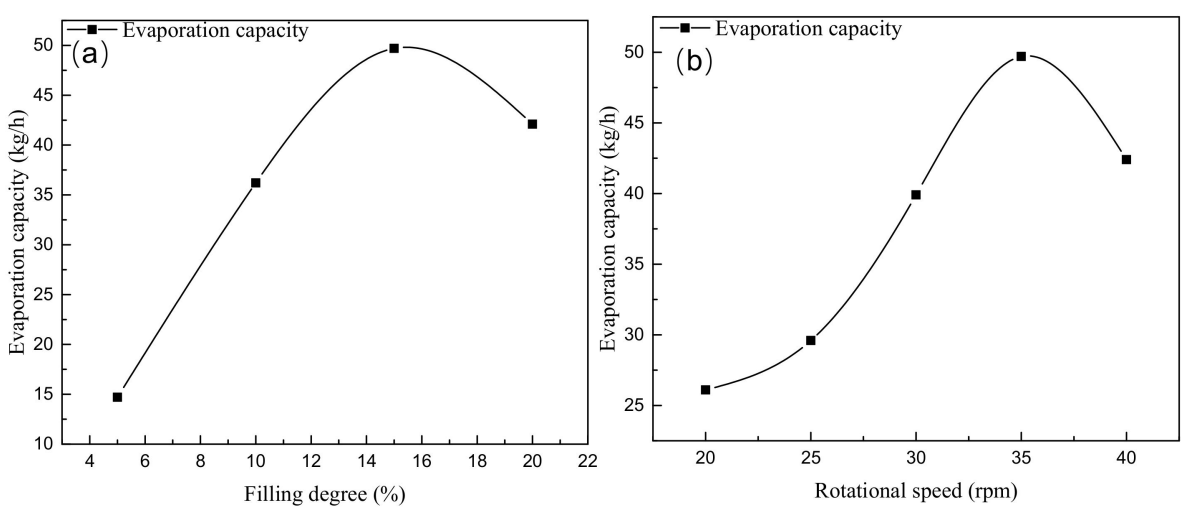

Figure 12. The variation trend of the evaporation capacity of high-salt wastewater as a function of the rotational speed (a) (the filling degree was 15\%) and the filling degree (b) (the rotational speed was fixed at $35 \mathrm{rpm}$ ). 
Table 5. Evaporation capacity of high-salt wastewater in different treatment methods.

\begin{tabular}{cc}
\hline Treatment Method & Evaporation Capacity (kg/h) \\
\hline Mechanical vapor recompression & $20[37]$ \\
The new rotary dryer & 49.7 \\
Spray evaporation tower & $28.8[38]$ \\
\hline
\end{tabular}

We also utilized this novel rotary dryer to treat the landfill leachate and investigated the effects of inlet air temperature on the drying performance. The experiments were conducted under the optimal operational conditions (with a rotational speed of $35 \mathrm{rpm}$ and a filling degree of $15 \%$ ) and the flow rate of the drying air was $1000 \mathrm{~m}^{3} / \mathrm{h}$. Figure $13 \mathrm{a}$ shows the variation trend of evaporation capacity as a function of inlet air temperature. With the increase of inlet air temperature, the values of evaporation capacity increase as well. When the inlet air temperature is $280^{\circ} \mathrm{C}$, the value of evaporation capacity is as large as $90 \mathrm{~kg} / \mathrm{h}$, since the drying air with higher temperature will transfer more heat to the wastewater. Figure 13b,c show the landfill leachate and the residues after drying, respectively, demonstrating the effectiveness of this novel rotary dryer to treat the landfill leachate. To our best knowledge, it is the first report that used a rotary dryer to treat the wastewater and realized the integration of evaporation and drying, as well as fulfilled the goal of zero-liquid discharge.
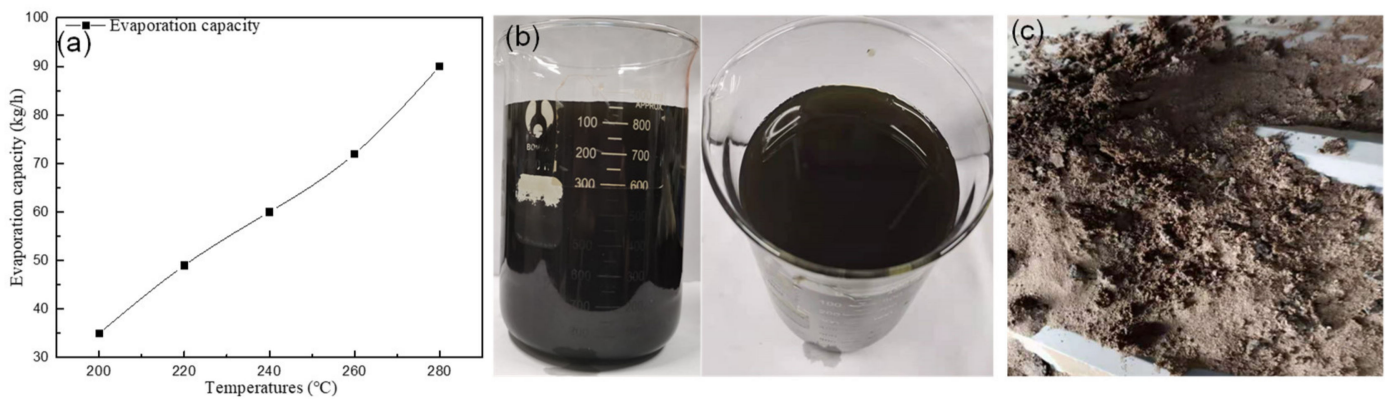

Figure 13. The results of evaporation capacity of the landfill leachate as a function of inlet air temperature (a); the landfill leachate (b) and the powder residue of landfill leachate after drying (c).

\section{Conclusions}

In this study, we employed numerical simulations to study the influences of flight structures (the angle in flights and the flight length), rotational speed, and beads filling degree on the motion behavior of alumina ceramic beads in the rotary drum, based on DEM. And then the optimized parameters were verified via field experiments and employed to treat the high-salt wastewater as well as the landfill leachate. The optimized flights are straight with a length of $65 \mathrm{~mm}$, and the optimized rotational speed and beads filling degree are $35 \mathrm{rpm}$ and $15 \%$, respectively. In the optimized conformation, the values of MAP and OAR are larger and the flow regime is the needed regime cataracting to realize a better drying performance. Besides, the simulated results of the motion of the beads' behavior are generally in good agreement with the experimental data for all studied factors. In the drying experiments, the evaporation capacity of high-salt wastewater is $49.7 \mathrm{~kg} / \mathrm{h}$ under the optimal operational conditions. The evaporation capacity of the landfill leachate increases with the increase of the inlet air temperature, and the evaporation capacity is as high as $90 \mathrm{~kg} / \mathrm{h}$ when the inlet air temperature is $280^{\circ} \mathrm{C}$. This compact ACB filled dryer with excellent drying performance provides a prototype for the integration of evaporation and drying to realize the zero-liquid discharge strategy of industrial wastewaters.

Author Contributions: Conceptualization, L.X. and S.X.; methodology, L.X. and S.X.; software, L.Y.; validation, L.Y. and L.S.; formal analysis, L.X. and W.Z.; investigation, L.Y. and L.S.; resources, L.X.; data curation, L.Y., L.S. and W.Z.; writing-original draft preparation, L.Y.; writing-review and 
editing, L.X., W.Z. and L.Y.; Visualization, L.X. and S.X.; supervision, S.X.; project administration, S.X.; funding acquisition, L.X. and W.Z. All authors have read and agreed to the published version of the manuscript.

Funding: This research was funded by the National Natural Science Foundation of China, grant number 22076137; This research was funded by the National Key Research and Development Program of China, grant number 2016YFC0401202; This research was funded by the open foundation of State Key Laboratory of Chemical Engineering, grant number SKL-ChE-20B02.

Institutional Review Board Statement: Not applicable.

Informed Consent Statement: Not applicable.

Data Availability Statement: Not applicable.

Acknowledgments: This work was supported by the National Natural Science Foundation of China (22076137), the National Key Research and Development Program of China (2016YFC0401202), and the open foundation of State Key Laboratory of Chemical Engineering (SKL-ChE-20B02).

Conflicts of Interest: The authors declare no conflict of interest.

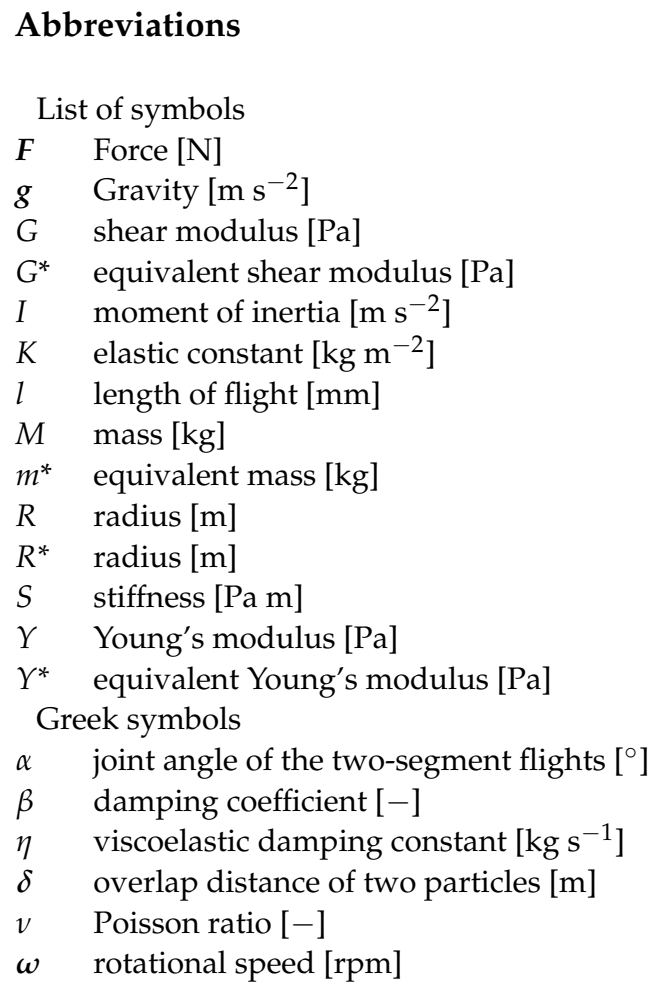

\section{References}

1. Lefebvre, O.; Moletta, R. Treatment of organic pollution in industrial saline wastewater: A literature review. Water Res. 2006, 40, 3671-3682. [CrossRef] [PubMed]

2. Fu, F.L.; Wang, Q. Removal of heavy metal ions from wastewaters: A review. J. Environ. Manag. 2011, 3, 407-418. [CrossRef] [PubMed]

3. Zhao, W.Y.; Zhou, M.; Yan, B.; Sun, X.; Liu, Y.; Wang, Y.; Xu, T.; Zhang, Y. Waste conversion and resource recovery from wastewater by ion exchange membranes: State-of-the-art and prospective. Ind. Eng. Chem. Res. 2018, 57, 6025-6039. [CrossRef]

4. Chang, Y.; Deng, L.; Meng, X.; Zhang, W.; Wang, C.; Wang, Y.; Zhao, S.; Lin, L.; Crittenden, J.C. Closed-Loop Electrochemical Recycling of Spent Copper(II) from Etchant Wastewater Using a Carbon Nanotube Modified Graphite Felt Anode. Environ. Sci. Technol. 2018, 10, 5940-5948. [CrossRef]

5. Bian, X.; Huang, Y.; Guo, R.; Xu, D.; Zhu, L.; Yang, J.; Qiu, Z. Research progress on salt separation and resource utilization in high salinity wastewater. Inorg. Chem. Ind. 2019, 51, 7-12.

6. Russo, T.; Fucile, P.; Giacometti, R.; Sannino, F. Sustainable Removal of Contaminants by Biopolymers: A Novel Approach for Wastewater Treatment. Current State and Future Perspectives. Processes 2021, 9, 719. [CrossRef] 
7. Revollar, S.; Meneses, M.; Vilanova, R.; Vega, P.; Francisco, M. Quantifying the Benefit of a Dynamic Performance Assessment of WWTP. Processes 2020, 8, 206. [CrossRef]

8. Fortes, M.C.B.; Silva, A.A.M.; Guimarães, R.C.; Ataide, C.H.; Barrozo, M.A.S. Pre-separation of siliceous gangue in apatite flotation. Ind. Eng. Chem. Res. 2007, 46, 7027-7029. [CrossRef]

9. Silvério, B.; Arruda, E.; Duarte, C.; Barrozo, M. A novel rotary dryer for drying fertilizer: Comparison of performance with conventional configurations. Powder Technol. 2015, 270, 135-140. [CrossRef]

10. Ding, Y.L.; Forster, R.; Seville, J.P.K.; Parker, D. Granular motion in rotating drums: Bed turnover time and slumping-rolling transition. Powder Technol. 2002, 124, 18-27. [CrossRef]

11. Xie, L.X.; Xu, S.C.; Su, L.B. A High Efficiency and Energy Saving Evaporative Drying Device. Chinese Patent CN201921638583.5, August 2019.

12. Hlosta, J.; Jezerská, L.; Rozbroj, J.; Žurovec, D.; Nečas, J.; Zegzulka, J. DEM investigation of the influence of particulate properties and operating conditions on the mixing process in Rotary Drums: Part 2-Process. Processes 2020, 8, 184. [CrossRef]

13. Nascimento, S.M.; Lima, R.M.; Brandão, R.J.; Duarte, C.R.; Barrozo, M.A.S. Eulerian study of flights discharge in a rotating drum. Can. J. Chem. Eng. 2019, 97, 477-484. [CrossRef]

14. Karali, M.A.; Specht, E.; Herz, F.; Mellmann, J.; Refaey, H.A. Unloading characteristics of flights in a flighted rotary drum operated at optimum loading. Powder Technol. 2018, 333, 347-352. [CrossRef]

15. Hlosta, J.; Jezerská, L.; Rozbroj, J.; Žurovec, D.; Nečas, J.; Zegzulka, J. DEM Investigation of the Influence of Particulate Properties and Operating Conditions on the Mixing Process in Rotary Drums: Part 1-Determination of the DEM Parameters and Calibration Process. Processes 2020, 8, 222. [CrossRef]

16. Höhner, D.; Wirtz, S.; Scherer, V. A study on the influence of particle shape and shape approximation on particle mechanics in a rotating drum using the discrete element method. Powder Technol. 2014, 253, 256-265. [CrossRef]

17. Nascimento, S.; Santos, D.; Barrozo, M.; Duarte, C. Solids holdup in flighted rotating drums: An experimental and simulation study. Powder Technol. 2015, 280, 18-25. [CrossRef]

18. Scherer, V.; Mönnigmann, M.; Berner, M.O.; Sudbrock, F. Coupled DEM-CFD simulation of drying wood chips in a rotary drum-Baffle design and model reduction. Fuel 2016, 184, 896-904. [CrossRef]

19. Benhsine, I.; Hellou, M.; Lominé, F.; Roques, Y. Influence of flight shape on discharging profiles of granular material in rotary dryer. EPJ Web Conf. 2017, 140, 03023. [CrossRef]

20. Nascimento, S.M.; De Lima, F.; Duarte, C.R.; Barrozo, M.A.D.S. Numerical Simulation and Experimental Study of Particle Dynamics in a Rotating Drum with Flights. Mater. Sci. Forum 2017, 899, 65-70. [CrossRef]

21. Henein, H.; Brimacombe, J.K.; Watkinson, A.P. Experimental study of transverse bed motion in rotary kilns. Met. Mater. Trans. B 1983, 14B, 191-205. [CrossRef]

22. Santos, D.A.; Barrozo, M.A.; Duarte, C.R.; Weigler, F.; Mellmann, J. Investigation of particle dynamics in a rotary drum by means of experiments and numerical simulations using DEM. Adv. Powder Technol. 2016, 27, 692-703. [CrossRef]

23. Sheehan, M.E.; Britton, P.F.; Schneider, P.A. A model for solids transport in flighted rotary dryers based on physical considerations. Chem. Eng. Sci. 2005, 60, 4171-4182. [CrossRef]

24. Geng, F.; Yuan, Z.; Xu, D. Three Dimensional Numerical Simulation of Mixing Process of Particles in Rotary Dryer. Chin. J. Appl. Mech. 2008, 25, 529-534.

25. Hill, K.M.; Kakalios, J. Reversible axial segregation of rotating granular media. Phys. Rev. E 1995, 52, 4393-4400. [CrossRef]

26. Havlík, J.; Dlouhý, T. Indirect Dryers for Biomass Drying-Comparison of Experimental Characteristics for Drum and Rotary Configurations. Chem. Eng. 2020, 4, 18. [CrossRef]

27. Xie, G.; Zhang, X.; Cai, J.; Sun, W.; Zhang, K.; Zhang, S. Development of a Novel Shaft Dryer for Coal-Based Green Needle Coke Drying Process. Appl. Sci. 2019, 9, 3301. [CrossRef]

28. Kaveh, M.; Abbaspour-Gilandeh, Y.; Taghinezhad, E.; Witrowa-Rajchert, D.; Nowacka, M. The Quality of Infrared Rotary Dried Terebinth (Pistacia atlantica L.)-Optimization and Prediction Approach Using Response Surface Methodology. Molecules 2021, 26, 1999. [CrossRef]

29. Silveira, J.C.; Brandao, R.J.; Lima, R.M.; Machado, M.V.; Barrozo, M.A.; Duarte, C.R. A fluid dynamic study of the active phase behavior in a rotary drum with flights of two and three segments. Powder Technol. 2020, 368, 297-307. [CrossRef]

30. Geng, F.; Li, Y.; Yuan, L.; Liu, M.; Wang, X.; Yuan, Z.; Yan, Y.; Luo, D. Experimental study on the space time of flexible filamentous particles in a rotary dryer. Exp. Therm. Fluid Sci. 2013, 44, 708-715. [CrossRef]

31. Thibault, J.; Alvarez, P.I.; Blasco, R.; Vega, R. Modeling the Mean Residence Time in a Rotary Dryer for Various Types of Solids. Dry. Technol. 2010, 28, 1136-1141. [CrossRef]

32. Jahani, M.; Farzanegan, A.; Noaparast, M. Investigation of screening performance of banana screens using LIGGGHTS DEM solver. Powder Technol. 2015, 283, 32-47. [CrossRef]

33. Cundall, P.A.; Strack, O.D.L. A discrete numerical mode for granular assemblies. Geotechnique 1979, 29, 47-65. [CrossRef]

34. Stevens, A.; Hrenya, C. Comparison of soft-sphere models to measurements of collision properties during normal impacts. Powder Technol. 2005, 154, 99-109. [CrossRef]

35. Le Guen, L.; Huchet, F.; Dumoulin, J.; Baudru, Y.; Tamagny, P. Convective heat transfer analysis in aggregates rotary drum reactor. Appl. Therm. Eng. 2013, 54, 131-139. [CrossRef] 
36. Chou, S.; Liao, C.; Hsiau, S. An experimental study on the effect of liquid content and viscosity on particle segregation in a rotating drum. Powder Technol. 2010, 201, 266-272. [CrossRef]

37. Zhou, Y.; Shi, C.; Dong, G. Analysis of a mechanical vapor recompression wastewater distillation system. Desalination 2014, 353, 91-97. [CrossRef]

38. Tang, Z.W.; Wang, J.; Huang, H.; Nie, C. Design of a spray evaporation tower for high-salinity oilfield waster and numerical simulation of its flow field. Environ. Technol. 2017, 35, 27-33. 